\title{
Effect of Compassion Focused Therapy (CFT) on level of Depression and Self- compassion
}

\author{
Vaishali Tiwari ${ }^{1}$, Blessy Antony ${ }^{2}$, M.K. Acharya ${ }^{3}$ \\ ${ }^{1}$ Lecturer, Department of Psychiatric Nursing, Choithram College of Nursing, Manikbagh Road, Indore. \\ ${ }^{2}$ Head, Department of Psychiatric Nursing, Choithram College of Nursing, Manikbagh Road, Indore. \\ ${ }^{3}$ Clinical Psychologist, Choithram Hospital and Research Centre (CH\&RC), Manikbagh Road, Indore. \\ Corresponding author: Vaishali Tiwari \\ Email - vaishali.tiwari999@gmail.com
}

\begin{abstract}
Background and Objectives: Depression conceptualizes variety of psychic and somatic syndromes and known as the 'common cold' of mental illness. Compassion Focused Therapy pays particular attention to the ability to generate affiliative motives, behaviors and emotions. Focusing on the experience and development of compassion has been found to reduce depression and self-criticism. The main aim of this study was to assess the efficacy of Compassion Focused Therapy on level of depression and self-compassion among patients with depression at selected hospitals of Indore.

Methods: A Quasi- experimental pre-test, post-test control group design was adopted. The population consisted of 12 patients with depression, those who were on antidepressants, were selected through nonprobability purposive sampling, then assigned 6 in each experimental and control group. Beck's Depression Inventory II and Neff's self-compassion scale were used for assessment of level of depression and selfcompassion. Compassion Focused Therapy was administered on experimental group for 15 days, followed by post -test and one month follow up. Control group was only on pharmacotherapy. The effect of compassion focused therapy computed by paired t-test.

Results: The mean score of level of depression in experimental group was 25.83 which had cut-down to 14.17 at post -test and 10.33 at one month follow up. Similarly mean pre- test score of level of selfcompassion in experimental patients was 2.54 which increased to 3.52 at post -test and 3.69 at one month follow up.

Conclusion: The major finding of the study reveals that Compassion Focused Therapy found efficient in reducing the level of depression and improving self-compassion.
\end{abstract}

Keywords: Compassion Focused Therapy, Depression, Self-compassion.

(Paper received $-7^{\text {th }}$ July 2018, Peer review completed $-20^{\text {th }}$ August 2018)

(Accepted $-24^{\text {th }}$ August 2018)

\section{INTRODUCTION}

Mood is a pervasive and sustained emotion that influences the individual's perception and his functioning in the world [1]. The term depression is extremely broad variably defining an effect, mood states, disorders or syndromes- as well as disease states, a depressed 'affect' usually occurs in response to a specific situation and is defined as a transient and non-substantive state of feeling 'depressed', 'sad' or 'blue'.

A depressed mood is more pervasive, more likely to be experienced an unusual or atypical, associated with negative ideation (hopelessness, helplessness, pessimism about the future), and may influence behaviour. Its quiet essential construct is lowering of the individual's intrinsic level of self-esteem. 
A depressive condition (be it a disorder, syndrome or disease) is generally distinguished by a longer duration, more clinical (and more pathological) features and distinct social impairments [2].

Recently conducted world mental health surveys indicate that major depression is experienced by $10-15 \%$ people in their lifetime and about $5 \%$ suffer from major depression in any given year. Lifetime prevalence of all depressive disorders taken together is over $20 \%$ that is one in five individuals [3].

The US Centre for Disease Control (CDC) 2006 and 2008 surveys of 235,067 adults from 45 states plus the District of Columbia, Puerto Rico, and US Virgin Islands found the rate of current depression (using the Patient Health Questionaire-8) to be $9 \%$ and the rate of those with a current diagnosis of major depression (DSM-IV criteria) to be $3.4 \%$. The high female: male sex ratio in the prevalence of depression, especially during the reproductive years, is one of the most replicated findings in epidemiology. French data from the European Study of the Epidemiology of Mental disorders supported this finding that globally, approximately twice as many women suffered from depression as men.

The burden of depressive disorder extends far beyond the disorder itself influencing the mortality risk of the patient. The standardized mortality ratio (SMR) for suicide in patients with unipolar depression is 20.9 in men and 27.0 in women. In other terms, depressed men and women are 20.9 and 27 times, respectively, more likely to commit suicide than the general population [4].

Recently attention has focused on the role of cultivating compassion for self and others. This is associated with generating positive emotions, particularly those associated with affiliation, connectedness and attachment. Indeed, there is now increasing evidence that helping people develop compassionate and affiliative feelings for others, and oneself, significantly contributes to mental health, well-being and social harmony and has a range of neurophysiological effects. Compassion focused therapy (CFT) pays particular attention to the ability to generate affiliative motives, behaviours and emotions. Focusing on the experience and development of compassion has been found to reduce depression, anxiety and self-criticism in people presenting to a community mental health team, in people with long term mental health problems, and people in a high security psychiatric setting [5].

\section{Need of the study}

Depression is one of the most common mental disorders, affecting 350 million people worldwide [6]. It has become a major public health problem, demonstrating a constant increase in prevalence. Its contribution to the global burden of disease is considerable, being the single most important cause of Years Lost due to Disability (YLD) in middle and high-income countries as well as the third cause of disability worldwide and accounting for $4.3 \%$ of total Disability Adjusted Life Years (DALY) [7].

Moreover, depression is an important cause of work absenteeism, loss of productivity, mortality and co morbidity such as anxiety disorders and substance abuse [8]. Up to $15 \%$ of clinically depressed and treated persons die by suicide [9].

Furthermore, due to the high rates of recurrence and persistence of depression symptoms, depression has become a significant economic burden associated with substantial use of health care resources.

Psychosocial disability is related to depressive symptom severity during the long-term course of unipolar major depression (MD). In a study of 371 patients with unipolar MD in the National Institute of Mental Health Collaborative Depression Study, monthly ratings of impairment in life functions and social relationships over an average of 10 years' follow-up were found to be associated with a degree of depressive symptom severity. Significant increases in disability occurred with each stepwise increment in depressive symptom severity (asymptomatic $>$ sub threshold depressive symptoms $>$ symptoms at the minor depression/dysthymia level > symptoms at the MD level) [10].

At a time when the depressed patient is at greatest need of social support, depression tends to disrupt family stability frequently leading to separation or divorce. The link between depression and divorce can be bidirectional. A study using the longitudinal component of the Canadian National Population Health Survey (1994/1995 through 2004/2005) examined the relationship between the dissolution of a marital or cohabiting relationship and subsequent depression among Canadians aged 20 to 64 years. For both sexes, dissolution of a marriage or cohabiting relationship was associated with higher odds of a new episode of depression, compared with those who remained with a spouse or partner over the 2-year period following 
the depressive episode. Marital dissolution was more strongly associated with depression among men than among women [4].

Few studies have investigated risk factors for suicidal ideation and attempts, or possible variations in them, among representative samples of psychiatric patients with major depressive disorder. During the current MDD episode, $58 \%$ of all patients had experienced suicidal ideation; among the $15 \%$ of the total who had attempted suicide, almost all (95\%) had also had suicidal ideation. In nominal regression models predicting suicidal ideation, hopelessness, alcohol dependence or abuse, low level of social and occupational functioning, and poor perceived social support were found to be significant $(p<.05)$ independent risk factors. High severity of depression and current alcohol dependence or abuse in particular, but also younger age and low level of social and occupational functioning, predicted suicide attempt [11].

Compassion has emerged as an important construct in studies of mental health and psychological therapy. Although an increasing number of studies have explored relationships between compassion and different facets of psychopathology there has as yet been no systematic review or synthesis of the empirical literature. A comparative study was conducted to compare self- compassion in clinically depressed patients and never depressed subjects, to investigate self- compassion and its relation to cognitive behavioural avoidance and rumination in depressed out patients and to investigate rumination and avoidance as mediators of the relationship between self- compassion and depressive symptoms. 142 depressed out patients and 120 never depressed individuals from community sample completed a self- report measure of self-compassion along with other measures. Results indicated that depressed patients showed lower levels of self-compassion than never depressed individuals, even when controlled for depressive symptoms. Since depressed patients seem to have difficulties adopting a self-compassionate attitude, psychotherapies are well advised to explore and address how depressed patients treat themselves [12].

A high prevalence of depression among general population gives indication towards immediate and psychiatric therapeutic interventions. In addition to the profound effects on the quality of life of the patient, depression has a major impact on mortality risk by suicide, and on cardiovascular and other diseases as well as death by all causes. Depression impairs cognitive and social functioning leading to decreased performance in the workplace and elsewhere.

While dealing with the patients with depression, researcher found that, a patient with depression expresses high shame, guilt and self-criticism and altered affect regulation system. While going through the literature it is found that CFT focuses on developing people's abilities to feel inner safeness and self-reassurance as an antidote to self-criticalness. It working with specific affect regulation systems. Keeping this view in mind the topic of the study is selected for the study.

\section{Problem statement}

A quasi experimental study to assess the effectiveness of Compassion Focused Therapy on level of Depression and self- compassion among patients with depression in selected hospitals of Indore in the year 2015-2016.

\section{Objectives of the study}

- To assess the level of depression among patients with depression in experimental and control group.

- To assess the level of self-compassion among patients with depression in experimental and control group.

- To evaluate the effectiveness of Compassion focused therapy at before therapy, after therapy and at one month follow- up of therapy on the level of depression among patients with depression in experimental group.

- To evaluate the effectiveness of Compassion focused therapy at before therapy, after therapy and at one month follow- up of therapy on the level of self-compassion among patients with depression in experimental group.

\section{Hypotheses}

- $\quad \mathbf{H}_{1}$ : There is a significant difference in the level of depression at before therapy, after therapy and after one month follow up among patients in the experimental group at the level $\mathrm{p} \leq 0.05$. 
- $\quad \mathbf{H}_{2}$ : There is a significant difference in the level of self-compassion at before therapy, after therapy and after one month follow up among patients in the experimental group at the level $\mathrm{p} \leq 0.05$.

\section{METHODOLOGY}

Setting: The study was conducted in Choithram hospital and research centre, with a Multidisciplinary Behavioural Psychiatric Intervention unit (MDBI).

Population: All Patients who were diagnosed with depression by the psychiatrist in selected hospitals of Indore.

Sample and sample size: The sample comprised of 12 patients with depression referred by the psychiatrist. Sampling technique: The sample was selected through Non- probability, purposive technique.

Tool: the tools used in the study are:

- Socio-demographic variables

- Clinical Performa

- Beck's Depression Inventory-II

- Neff's self-compassion scale

Validity and reliability of the tool:

The socio demographic variables, clinical Performa and standardized tools Beck depression inventory-II and Neff's self - compassion scale along with the objectives, hypothesis and criteria checklist was submitted to 5 experts in the field of Mental Health Nursing for establishing content validity. Necessary changes were made as per the recommendations and comments of the experts. Researcher has used standard tools:

1. Beck's Depression Inventory is a standardized and a self-report instrument that measures depth of Depression. It contains 21 categories of symptoms and attitudes. The highest possible total for the whole test would be sixty- three and the lowest possible score for the test would be zero. The responses were scored into 6 level of severity as follows:

11-16 = Mild mood disturbance

$17-20=$ Borderline clinical Depression

21-30 $=$ Moderate depression

31-40 $=$ Severe depression

$>40=$ Extreme depression

Beck depression inventory-II (BDI-II) reported an average alpha coefficient around 0.9, ranging from $\mathrm{r}=0.83$ to 0.96 . (Standardized tool)

2. Self-Compassion Scale: measures the degree to which individuals display self-kindness against selfjudgment, common humanity versus isolation, and mindfulness versus over-identification. The Self-Compassion Scale (SCS) consists of 26 items. It is Presented on a Likert scale, ranging from 1 (almost never) to 5 (almost always), those completing the SCS are able to gain insight on how they respond to themselves during a struggle or challenging time.

The responses of 6 subscales were scored into 3 level of severity as follows:

1-2.5 = Low self-compassion

2.6-3.5 = Moderate self-compassion

3.6-5.0 = High self-compassion

Test-retest reliability correlations of self-compassion scale was $r=0.93$. (Standardized tool)

\section{Procedure for data collection}

Written permission was obtained from the administrative authorities of the hospital prior to data collection and informed consent was taken from the patients. A total of 12 samples were selected for the studies, who were referred by the psychiatrist. There were 6 patients each in experimental and control group. Time taken for filling up the questionnaire was 15-20 minutes. All 6 patients who were in experimental group were explained thoroughly about the therapy and daily practices of the sessions. Therapy was performed in 15 sessions for 60 minutes, which spread over a period of 15 days. During the data collection Beck depression 
inventory and self -compassion scale were used to assess the level of depression and self-compassion. Assessment of level of depression and self-compassion of both experimental and control group patients was done on the first day, $15^{\text {th }}$ day and after one month.

\section{Compassion focused therapy}

In this study Compassion Focused Therapy refers to soothing rhythm breathing, compassion focused imagery work, compassion flowing out and into oneself: using memory and compassionate letter writing, which would be done in 15 sessions. The duration of each session will be 60 minutes.

- Soothing rhythm breathing: It is the process to practice the breathing without "judging and evaluating thoughts"; this will be done by practicing "Mindful Relaxation".

- Compassion focused imagery work: It refers to try and create feelings to stimulate a particular kind of brain system through patient's imagery. Such as...

$\checkmark \quad$ Imagine a wind gently on your face

$\checkmark \quad$ Hear the gentle Hushing of the waves on the sand

$\checkmark \quad$ Beautiful beach with a crystal blue sea.

$\checkmark \quad$ Imagine soft sand under your feet.

$\checkmark \quad$ Pleasant places

- Compassion flowing out and into one: using memory: Imagine kindness and compassion flowing from patient to others and others to patient.

It will be performed by recalling the feelings associated with events when a patient felt very kind and caring towards someone and bring memory of a time when someone was kind with patient.

- Compassionate letter writing: This include write about difficulties, but from the compassionate part of us.

\section{RESULTS}

The data was analysed according to the objectives of the study using descriptive and inferential statistics.

\section{Section I: Socio demographic characteristics of patients}

The present study showed that all patients in experimental group were equally divided i.e. $2(33.3 \%)$ in age groups of 21-30 years, 31-40 years and 41-50 years. While in control group 3 patients (50.0\%) belonged to the age group of 31-40 years and $2(33.3 \%)$ belonged to the age group of 21-30 years. Majority of patients, i.e. $5(83.3 \%)$ were females in both groups. Viewing educational qualification, in experimental group majority i.e., $3(50 \%)$ were graduate, $2(33.3 \%)$ did post- graduation \& Where as in control group majority, $3(50 \%)$ were graduate. Regarding religion all 12 patients $(100 \%)$ were Hindu. marital status, in experimental group, all 6 patients $(100 \%)$ were married while in control group 4 patients $(66.6 \%)$ were married. In experimental group, 3 patients (50\%) had two siblings, 2 patients (33.3\%) had more than three siblings, though in control group 2 patients $(33.3 \%)$ had two siblings, $2(33.3 \%)$ had more than three siblings. Considering ordinal position, in experimental group, all the patients were equally distributed, i.e. 2 (33.3\%) as the oldest, youngest and in middle position. while in the control group 2 patients (33.3\%) were first born child, 2(33.3\%) were second born child.

In family type, in experimental group 3 patients were belonged from nuclear family and $3(50 \%)$ were belonged from joint family though, in control group, majority of 4 patients $(66.7 \%)$ were belonged from joint family. In experimental group majority of patients i.e. 5 patients $(83.3 \%)$ had two children, whereas in control group $3(50 \%)$ had two children. In experimental group majority of $4(66.6 \%)$ patients had come from urban areas and in control group also, majority of 5(83.3\%) were from urban areas. Regarding occupation, in experimental group. Majority of 5 patients (83.3\%) were home makers whereas in control group 4 patients (66.7\%) home makers and 2 patients (33.3\%) were employed. In relation to monthly income of the family in experimental group majority of 4 patients (66.6\%) were having more than Rs. 15000/income. Though among control group 4 patients had monthly income more than Rs. 15000/- and only 2 patients (33.3\%) had income of Rs. 10001- Rs.15000/-. 


\section{Section II: Clinical profile of clients}

Regarding family history of psychiatric illness; in experimental group 5 patients $(83.3 \%)$ did not have any family history of psychiatric illness but only 1 patient (16.7\%) had history of psychiatric illness in the family. Whereas in control group 4 patients (66.75) did not have any account of psychiatric illness in the family but only 2 patients (33.3\%) had history of psychiatric illness in the family. All the 12 patients (100\%) among both groups group were receiving treatment since less than one year. In relation to undergone psychotherapy or counselling, all the 12 patients $(100 \%)$ in both groups did not undergo any psychological therapy or counselling process during the past one year. Viewing practice of meditation or yoga therapy, in experimental group 5 patients (83.3\%) did not practice yoga/ meditation, only one (16.7\%) had practice of yoga. while in control group no one had the practice of yoga/ meditation.

\section{Section III: Assessment of level of depression and self- compassion before intervention}

\section{Distribution of pre- test level of depression of patients in experimental and control group.}

Data presented in figure 1, reveals the of pre- test level of depression of patients in experimental and control group. Before the intervention, in experimental group 4 patients $(66.7 \%)$ had moderate depression, 2 patients $(33.3 \%)$ had borderline clinical depression. Whereas in control group, 3 patients $(50 \%)$ had moderate level of depression, 3 patients $(50 \%)$ had borderline clinical depression.

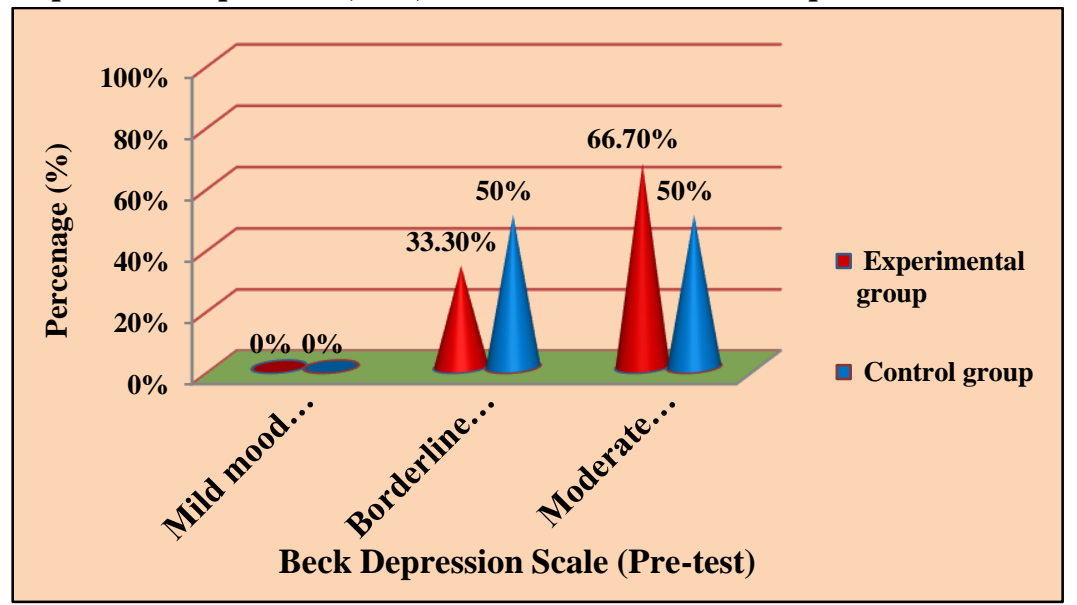

Figure 1: Cone Diagram showing the distribution of Pre-test level of Depression

Data presented in fig. 2 shows that, in both experimental and control groups, 3 patients (50\%) had low level of self- compassion and 3 patients had moderate level of self-compassion during pre-test assessment.

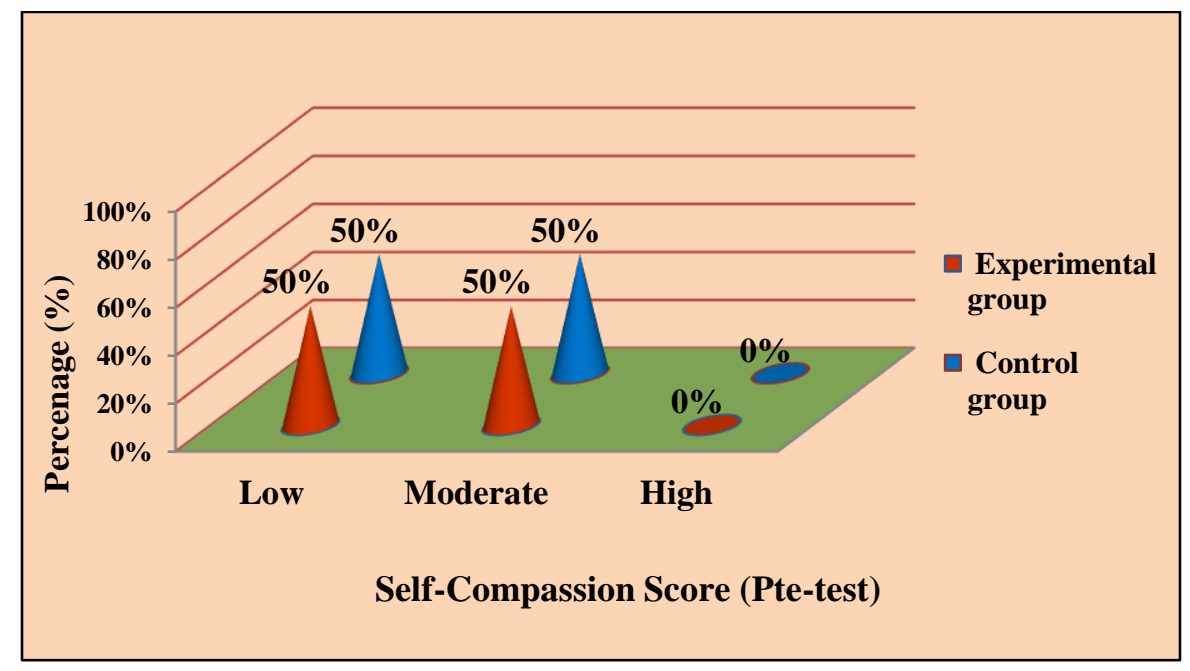

Figure 2: Cone Diagram showing the distribution of Pre-test level of Self-compassion 
Assessment of Effectiveness of Compassion Focused Therapy in experimental group.

Table 1: Paired sample ' $t$ ' test for Pre-test and post-test Beck depression scores of Experimental group, $(\mathrm{N}=6)$

\begin{tabular}{|c|c|c|c|c|c|c|c|}
\hline BDI score & Mean & $\begin{array}{c}\text { Difference } \\
\text { of means }\end{array}$ & SD & SE & df & ' $t$ ' value & $\begin{array}{l}\text { Table } \\
\text { value }\end{array}$ \\
\hline Pre-test & 25.83 & \multirow[t]{2}{*}{11.66} & 5.38 & 5.30 & \multirow[t]{2}{*}{5} & \multirow{2}{*}{$\begin{array}{c}6.348 \\
S^{*}\end{array}$} & \multirow[t]{2}{*}{2.57} \\
\hline Post -test & 14.17 & & 2.48 & 11.54 & & & \\
\hline
\end{tabular}

$\mathbf{P} \leq 0.05$ * significant, NS - Non significant, $\mathrm{S}$ - Significant

As per the depiction of table 1 the mean score level of depression was 25.83 at pre-test, which had decreased at post-test to 14.17. It shows the decreased level of depression. The mean difference was 11.66 with Pre-test $\mathrm{SD}$ of \pm 5.38 and post-test SD of \pm 2.48 . The computed ' $\mathrm{t}$ ' value was 6.348 at degree of freedom of 5 . This indicated that there was significant reduction in pre-test and post-test scores after compassion focused therapy at the level $\mathrm{P} \leq 0.05$.

Table 2: Paired sample ' $t$ ' test for post-test and one month follow up Beck depression scores of Experimental group

\begin{tabular}{|c|c|c|c|c|c|c|c|}
\hline BDI score & Mean & $\begin{array}{c}\text { Difference } \\
\text { of means }\end{array}$ & SD & SE & df & 't' value & $\begin{array}{l}\text { Table } \\
\text { value }\end{array}$ \\
\hline Post Test & 14.17 & \multirow[t]{2}{*}{3.84} & 2.48 & 3.80 & \multirow[t]{2}{*}{5} & \multirow{2}{*}{$\begin{array}{c}6.379 \\
S^{*}\end{array}$} & \multirow[t]{2}{*}{2.57} \\
\hline $\begin{array}{l}\text { One month } \\
\text { follow up }\end{array}$ & 10.33 & & 2.25 & 4.17 & & & \\
\hline
\end{tabular}

$\mathbf{P} \leq 0.05 *$ significant $\mathrm{NS}$ - Non significant $\mathrm{S}$ - Significant

Data presented in table 2 shows the mean score level of depression was 14.17 at post -test, which had decreased at one month follow up to 10.33. It depicts the decreased level of depression. The mean difference was 3.84 with Post-test SD of \pm 2.48 and one month follow up SD of \pm 2.25 . The computed ' $t$ ' value was 6.379 at degree of freedom of 5 . This indicated that there was significant reduction in post-test and one month follow up scores after compassion focused therapy at the level $\mathrm{P} \leq 0.05$. Hence research hypothesis $\mathrm{H}_{1}$ is accepted.

Table 3: Paired sample ' $t$ ' test for Pre-test and post-test Self-compassion scores of Experimental group.

\begin{tabular}{|c|c|c|c|c|c|c|c|}
\hline $\begin{array}{l}\text { Self- } \\
\text { compassion } \\
\text { score }\end{array}$ & Mean & $\begin{array}{c}\text { Difference } \\
\text { of means }\end{array}$ & SD & SE & Df & 't' value & $\begin{array}{l}\text { Table } \\
\text { value }\end{array}$ \\
\hline Pre-test & 2.54 & \multirow[t]{2}{*}{0.98} & 0.50 & 3.37 & \multirow[t]{2}{*}{5} & \multirow{2}{*}{$\begin{array}{c}6.488 \\
S^{*}\end{array}$} & \multirow[t]{2}{*}{2.57} \\
\hline Post -test & 3.52 & & 0.58 & 2.96 & & & \\
\hline
\end{tabular}

$\mathbf{P} \leq 0.05 *$ significant, NS - Non significant, $\mathrm{S}$ - Significant

As per the depiction of table 3 the mean score level of self- compassion was 2.54 at pre-test, which had increased at post-test to 3.52. It shows the increased level of self-compassion. The mean difference was 0.98 with Pre-test SD of \pm 0.50 and post-test SD of \pm 0.58 . The computed ' $t$ ' value was 6.488 at degree of freedom 
of 5. This indicated that there was significant improvement in pre-test and post-test scores after compassion focused therapy at the level $\mathrm{P} \leq 0.05$.

Table 4: Paired sample ' $t$ ' test for post-test and one month follow up of self-compassion scale scores of Experimental group, $(\mathrm{N}=6)$

\begin{tabular}{|l|c|c|c|c|c|c|c|}
\hline $\begin{array}{l}\text { Self- } \\
\text { compassion } \\
\text { score }\end{array}$ & Mean & $\begin{array}{c}\text { Difference } \\
\text { of means }\end{array}$ & SD & SE & df & 't' value & $\begin{array}{c}\text { Table } \\
\text { value }\end{array}$ \\
\cline { 1 - 6 } Post Test & 3.52 & 0.17 & 0.58 & 0.52 & 5 & 5.735 & 2.57 \\
\cline { 1 - 2 } $\begin{array}{l}\text { One month } \\
\text { follow up }\end{array}$ & 3.69 & & 0.51 & 0.58 & & $\mathrm{~S}^{*}$ & \\
\hline
\end{tabular}

$\mathrm{P} \leq \mathbf{0 . 0 5}{ }^{*}$ significant, NS - Non significant, S - Significant

Data presented in table 4 shows the mean score level of self-compassion was 3.52 at post -test, which had improved at one month follow up to 3.69. It depicts the increased level of self-compassion. The mean difference was 0.17 with Post-test SD of \pm 0.58 and one month follow up SD of \pm 0.51 . The computed ' $t$ ' value was 5.735 at degree of freedom of 5 . This indicated that there was significant enhancement in post-test and one month follow up scores after compassion focused therapy at the level $\mathrm{P} \leq 0.05$. Hence research hypothesis $\mathrm{H}_{2}$ is accepted.

\section{DISCUSSION}

The findings of the study revealed that in experimental group 4 patients $(66.7 \%)$ had moderate depression, $2(33.3 \%)$ had borderline clinical depression. Whereas in control group, 3 patients $(50 \%)$ had moderate level of depression, 3 patients $(50 \%)$ had borderline clinical depression.

In control group equal number of patients i.e. $3(50 \%)$ had Border line clinical depression and $3(50 \%)$ had moderate level of depression.

Similar findings obtained in study conducted by Sanja Music Milanovic et al (2014) to assess the prevalence of patients with unrecognised depression symptoms in general practice. Descriptive statistics was used and results showed that out of 769 participants $25.5 \%$ of participants were outside the normal range, $19.38 \%$ were mildly, $4.64 \%$ moderately, and $0.91 \%$ severely depressed [13].

\section{Assessment of level of self-compassion}

It was found that, in both experimental and control groups, 3 patients $(50 \%)$ had low level of self- compassion and 3 patients had moderate level of self-compassion.

Likewise, Kristine D. Neff. Germer (2015) conducted a study to examine the effect of Mindfulness SelfCompassion (MSC) program, on wellbeing using measures of happiness, life satisfaction, depression, and stress among 24 participants. Study outcomes showed that 9 (75\%) participants had low level of selfcompassion and 3(25\%) had high level of self-compassion in interventional group. In control group 7 (58.4\%) participants had low self-compassion and 5(41.6\%) had moderate self- compassion [14].

\section{Efficacy of compassion focused therapy}

Statistical results revealed that mean pre- test score of experimental patients was 25.83 which decreased to 14.17 at post -test and further reduced to 10.33 at one month follow up. This indicated that there was significant difference in the mean Beck depression scale scores at pre, post and one month follow up of the experimental group at the level $\mathrm{P} \leq 0.05$. Hence, the research Hypotheses $\mathrm{H}_{1}$ was accepted.

7 the mean score level of self- compassion was 2.54 at pre-test, which had increased at post-test to 3.52 , which further improved at one month follow up to 3.69. It depicts the increased level of self-compassion. 
This indicated that there was significant enhancement in post-test and one month follow up scores after compassion focused therapy at the level $\mathrm{P} \leq 0.05$. Hence research hypothesis $\mathrm{H}_{2}$ is accepted.

Similar findings can be comparable to a study conducted by Chris Irons et al (2010), investigate the use of compassionate images in a self- help group of depressive and self- critical people. The study included 18 participants of self- help depression group $(\mathrm{n}=18, \mathrm{M}=8, \mathrm{~F}=10)$, who had diagnosis of depression and were on antidepressant drugs. Findings of paired $t$ test revealed the reduction in scores for depression was significant. In regard to self-soothing/compassion there was a significant increase in ease of generating these images and soothing oneself in self-critical situation $[16,17]$.

Although the data is statistically not significant, but there is difference in level of depression and selfcompassion at post-test and one month follow up of therapy in experimental group as compared to control group. In experimental group, it was observed that, there is reduction in behavioural and emotional aspects such as pessimism, sadness of mood, crying spells, self-criticism and suicidal ideation of patients as well as somatic complaints such as lack of sleep, fatigue and lack of appetite.

On the contrary in control group it was seen that there is reduction in somatic symptoms rather than behavioural and emotional aspects.

\section{CONCLUSION}

The researcher realized that the study was very useful for patients with depression. She also concluded that females, particularly married females were mainly affected by depression. Investigator during her study found that due to interpersonal conflicts with in laws, marital disharmony, forced marriages and family obligations most of the females (70\%) were developing depression. So, researcher found need of further studies on effect of compassion focused therapy for females having marital or family discord.

\section{REFERENCES}

1. Sadock BJ, Sadock VA, Kaplan \& Sadock. Mood disorders, Synopsis of Psychiatry. 10 ${ }^{\text {th }}$ ed. New Delhi: Wolters Kluwer Lippincott Williams \& Wilkins. 2007.

2. Gelder Michael, Nancy Andresen, Juan Lopez Ibor, John Geddes. New Oxford Text book of Psychiatry. $2^{\text {nd }}$ ed. 2012.

3. Pattanayak RD, Sagar R. Depressive disorders in Indian context: a review and clinical update for physicians. J Assoc Physicians India 2014;62:827-32.

4. Lépine JP, Briley M. The increasing burden of depression. Neuropsychiatr Dis Treat 2011;7(Suppl 1):3-10.

5. Gilbert P, Allan S, Brough S, Melley S, Miles JN. Relationship of anhedonia and anxiety to social rank, defeat and entrapment. J Affect Disord 2002;71(1-3):141-51.

6. World Health Organization. WHO Global Burden of Disease. Geneva; 2012 Feb. Availablefrom.http://www.who.int/healthinfo/globalburdendisease/GBDreport2004updatefull.pdf.

7. World Health Organization. mhGAP intervention guide for mental, neurological and substance use disorders in non-specialized health settings. Geneva: who Publications; 2008. Available from http://whqlibdoc.who.int/publications/2010/9789241548 069_eng. pdf.

8. Maier W, Falkai P. The epidemiology of comorbidity between depression, anxiety disorders and somatic diseases. Int Clin Psychopharmacol 1999;14:S1-6.

9. Bostwick JM, Pankratz VS. Affective disorders and suicide risk: a reexamination. Am J Psychiatry 2000;157(12):1925-32.

10. Balkrishnan R, Joish VN, Yang T, Jayawant SS, Mullins CD. The economic burden associated with SSRI treatment failure in a managed care population. J Med Econ 2008;11(4):601-10.

11. Sokero TP, Melartin TK, Rytsälä HJ, Leskelä US, Lestelä-Mielonen PS, Isometsä ET. Prospective study of risk factors for attempted suicide among patients with DSM-IV major depressive disorder. Br J Psychiatry 2005;186(4):314-8.

12. Krieger T, Altenstein D, Baettig I, Doerig N, Holtforth MG. Self-compassion in depression: Associations with depressive symptoms, rumination, and avoidance in depressed outpatients. Behav Ther 2013;44(3):501-13.

13. Musić Milanović S, Erjavec K, Poljičanin T, Vrabec B, Brečić P. Prevalence of depression symptoms and associated socio-demographic factors in primary health care patients. Psychiatr Danub 2015;27(1):20-37.

14. Neff KD, Germer CK. A pilot study and randomized controlled trial of the mindful self- compassion program. J Clin Psychol 2013;69(1):28-44.

15. Poongothai S, Pradeepa R, Ganesan A, Mohan V. Prevalence of depression in a large urban South Indian population-The Chennai Urban Rural Epidemiology study (CURES-70). PloS One 2009;4(9):e7185.

16. Grover S, Dutt A, Avasthi A. An overview of Indian research in depression. Indian J Psychiatry 2010;52(Supp11):S178-85 
17. Gilbert P, Irons C. A pilot exploration of the use of compassionate images in a group of self- critical people. Memory 2004;12(4):507-16.

Acknowledgements - The first author acknowledges the patients who participated in this study. Author also thank to Dr. Ashish Goyal, Consultant Psychiatrist, Choithram Hospital and Research Centre, Indore for his expert guidance and co-operation.

Conflict of Interest - Nil.

Funding - Nil. 